\title{
First-principles study of the structural, electronic, and elastic properties of $\mathrm{Sc}_{2} \mathrm{SiX}(\mathrm{X}=\mathrm{C}, \mathrm{N})$
}

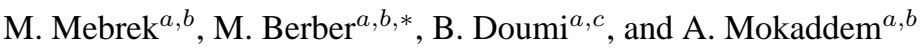 \\ ${ }^{a}$ Laboratoire d'Instrumentation et Matériaux Avancés, \\ Centre Universitaire Nour Bachir El-Bayadh, BP 900 route Aflou, 32000, Algérie. \\ *e-mail: berbermohamed@yahoo.fr \\ *ORCID: http://orcid.org/0000-0003-1285-3070 \\ ${ }^{b}$ Centre Universitaire Nour Bachir El Bayadh, 32000 El Bayadh, Algérie. \\ ${ }^{c}$ Faculty of Sciences, Department of Physics, Dr. Tahar Moulay University of Saida, 20000 Saida, Algeria.
}

Received 6 September 2020; accepted 7 December 2020

Using ab-initio calculations, we studied the structural, elastic, and electronic properties of $\mathrm{Sc}_{2} \mathrm{SiX}_{\mathrm{X}}$ compounds with, $(\mathrm{X}=\mathrm{C}$, $\mathrm{N})$. The negative formation energy and the positive cohesive energy indicate that these compounds are energetically stable and can be synthesized in normal conditions. $\mathrm{Sc}_{2} \mathrm{SiC}$ and $\mathrm{Sc}_{2} \mathrm{SiN}$ compounds are mechanically stable, estimated by the individual elastic constants. Elastic constants and modulus increase when $\mathrm{C}$ is substituted by $\mathrm{N}$. The elastic anisotropy in $\mathrm{Sc}_{2} \mathrm{SiC}$ is high compared to $\mathrm{Sc}_{2} \mathrm{SiN}$. Both nanolaminates are fragile in nature. $\mathrm{Sc}_{2} \mathrm{SiC}$ is more conductive than $\mathrm{Sc}_{2} \mathrm{SiN}$. The calculated electron band structures and the density of states imply that the chemical bond in two compounds is a combination of covalent, ionic, and metallic nature. The main factors governing the electronic properties are the hybrid states Sc- 3d, Si-3p, and C -2p and the bond (p-d) stabilizes the structure. Fermi's surface characteristics have been studied for the first time, which are changed when replacing $\mathrm{N}$ by $\mathrm{C}$. Based on the estimate of the total energy, we conclude that the replacement of $\mathrm{C}$ by $\mathrm{N}$ will lead to a stabilization of the hexagonal structure and a decrease of the metallic support.

Keywords: MAX phases; ab-initio calculations; structural properties; electronic properties; elastic properties.

PACS: 71.15.Mb; 71.20.-b; 73.20.At; 71.18.+y

DOI: https://doi.org/10.31349/RevMexFis.67.500

\section{Introduction}

Tha MAX phases, the extension of the Hägg phases known since 1960 when Nowotny reported the discovery of more than 100 carbides and nitrides [1,2], represent an exceptionally extensive class of ceramics. They correspond to a general formula of the type: $\mathrm{M}_{n+1} \mathrm{AX}_{n}$ where $\mathrm{M}$ is a transition metal (Ti, V, Cr), A is a metal in general groups IIIA or IVA (Al, Si, $\mathrm{P}, \mathrm{S})$ and $\mathrm{X}$ is either $\mathrm{C}$ and/or $\mathrm{N}$, and $n=1,2,3$ [2,3]. Despite their relatively old discovery, their physical properties have been relatively little studied and it was not until 1996 that a systematic work of synthesis and characterization was undertaken by an American team from Drexel University (Philadelphia) led by Mr. Barsoum [4]. Most of the MAX phases are of $\mathrm{M}_{2} \mathrm{AX}$ stoichiometry with the space group P63 / mmc [5]. Figure 1 shows the crystal structure of $\mathrm{Sc}_{2} \mathrm{SiX}$. These $\mathrm{M}_{2} \mathrm{AX}$ has attracted more attention due to the fundamental properties, usually associated with both metals and ceramics [6]. In general, MAX phases showcase a metallic behavior [7-12], are good electrical and thermal conductors [13], have a high elastic modulus [13], are machinable [14], resitant to oxidation, tolerant to damage, elastically rigid, and present low thermal expansion [15]. Additionally, they have excellent thermal shock and corrosion resistance $[16,17]$. In addition, MAX phases are used as the replacement of machinable ceramics, furnace cabinets, wear and corrosion protection, heat exchangers, applications in which rotating parts are used,

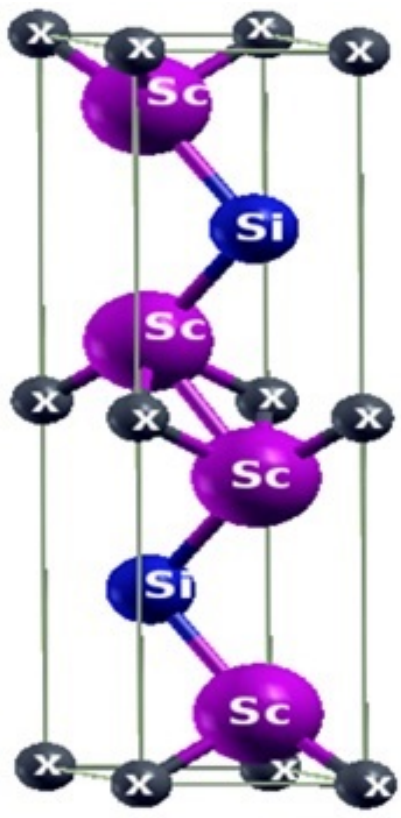

FIGURE 1. Crystal structure of $\mathrm{Sc}_{2} \operatorname{SiX}(\mathrm{X}=\mathrm{C}, \mathrm{N})$.

low friction applications based on the lubricating power of the basal plane [18]. In this work, the idea of the existence of a new class of superconducting materials. Despite all the efforts, it is obvious that the $\mathrm{Sc}_{2} \mathrm{SiC}$ and $\mathrm{Sc}_{2} \mathrm{SiN}$ MAX phase's compounds have not been subjected to theoretical and ex- 
perimental studies. The purpose of our work is to calculate and study the structural, electronic, and elastic properties of the compounds $\mathrm{Sc}_{2} \mathrm{SiC}$ and $\mathrm{Sc}_{2} \mathrm{SiN}$ MAX phases, using first-principle calculations of density functional theory (DFT) within the full-potential linearized augmented planewave (FP-LAPW) approach. This document is organized as follows: computational details are described in Sec. 2, the results are discussed in Sec. 3, and finally, gives the conclusions.

\section{Computational detail}

Today, there are several codes with a wide variety of approximations that we can make use of for a theoretical study. In our calculations, we used the first-principle methods of density functional theory (DFT) based on the full-potential linearized augmented plane-wave (FP-LAPW) approach as implemented in WIEN2K code $[19,20]$. This application allowed us to study the structural, electronic, and mechanic properties of max phase types $\mathrm{M}_{n+1} \mathrm{~A} \mathrm{X}$ or $\mathrm{M}=\mathrm{Sc}, \mathrm{A}=\mathrm{Si}$, $(\mathrm{X}=\mathrm{C}, \mathrm{N}), n=1-3[1,2]$. The algorithm is based on the density functional theory (DFT) within the local density approximation (LDA) proposed by Perdew and Wang [21] for the exchange correlations functional. It calculates the selfconsistent solution of the equations of Kohn and Sham [22]. The electronic configurations of the sets of the system studied are Sc:[Ar] $4 \mathrm{~s}^{2} 4 \mathrm{~d}^{1}, \mathrm{Si}:[\mathrm{Ne}] 3 \mathrm{~s}^{2} 3 \mathrm{p}^{2}, \mathrm{~N}:[\mathrm{He}] 2 \mathrm{~s}^{2} 2 \mathrm{P}^{3}$ and $\mathrm{C}:[\mathrm{He}] 2 \mathrm{~s}^{2} 2 \mathrm{P}^{3}$. We have chosen radii Rmt such that there will be no overlap of the Muffin-Tin spheres; the values used are 2.6, 1.9, 2.8,1.6 for the $\mathrm{Sc}, \mathrm{Si}, \mathrm{C}$, and $\mathrm{N}$ atoms, respectively. The number of points $k$ used in the integration of the first Brillouin zone is (1500 k-points) for our structure this integration of $k$ on the Brillouin zone is carried out using the Monkhorst and Pack of mesh [23], and $\mathrm{R}_{m t} * \mathrm{~K}_{\max }$ is taken equal to 7 (where $\mathbf{R}_{m t}$ represents the smallest radius MuffinTin and $K_{\max }$ the cut-off of plane waves), within the spheres, the wave functions of the valence region extend to $l_{\max }=10$.

\section{Results and discussion}

\subsection{Structural properties}

Both $\mathrm{Sc}_{2} \mathrm{SiC}, \mathrm{Sc}_{2} \mathrm{SiN}$ compounds crystallize in the $\mathrm{Cr}_{2} \mathrm{AlCd}$ crystal structure. The positions of atoms in $\mathrm{Sc}_{2} \mathrm{SiX},(\mathrm{X}=\mathrm{C}$, $\mathrm{N})$ are as follows: $\mathrm{C}$ atoms are placed at the positions (0, $0,0)$, the $\mathrm{Si}$ atoms are at $(1 / 3,2 / 3,3 / 4)$ and the $\mathrm{Sc}$ atoms are at $\left(1 / 3,2 / 3, Z_{M}\right)[12]$, where $z$ is the internal free coordinate. We have first minimized the internal parameters $\mathrm{Z}_{M}$ by taking random lattice parameters to start our calculations because of the lack of any a priori information. We then performed detailed structural optimizations by reducing all energies to a minimum. Our results of the calculated lattice constants $a$ and $c$, bulk modulus and its pressure derivative, and the optimized free internal parameters obtained with the LDA functional at $0 \mathrm{~K}$ are reported in Table $\mathrm{I}$ for $\mathrm{Sc}_{2} \mathrm{SiC}$ and $\mathrm{Sc}_{2} \mathrm{SiN}$. These properties were determined by adjusting the
TABLE I. The equilibrium lattice parameters $(a, c$, and $c / a)$, equilibrium volume, internal parameter $\mathrm{Z}(\mathrm{M})$, bulk modulus $\left(\mathrm{B}_{0}\right)$ in $(\mathrm{GPa})$ and its pressure derivative (B') for $\mathrm{Sc}_{2} \mathrm{SiX}(\mathrm{X}=\mathrm{C}, \mathrm{N})$.

\begin{tabular}{cccccccc}
\hline & $\mathrm{a}(\AA)$ & $\mathrm{c}(\AA)$ & $\mathrm{c} / \mathrm{a}$ & $\mathrm{B}_{0}$ & $\mathrm{~B}^{\prime}$ & $\mathrm{Z}(\mathrm{M})$ & $V_{0}\left(\AA^{3}\right)$ \\
\hline $\mathrm{Sc}_{2} \mathrm{SiC}$ & 3.18 & 13.52 & 4.24 & 130.7 & 4.03 & 0.0893 & 116.76 \\
$\mathrm{Sc}_{2} \mathrm{SiN}$ & 3.16 & 13.36 & 4.26 & 151.5 & 4.12 & 0.0886 & 108.29 \\
\hline
\end{tabular}

total energy as a function of volume, using the Murnaghan equation [24]. The report $(c / a)$ is in good agreement with the ideal values $(\mathrm{Z}=1 / 12=0.0833)$ and with the theoretical compactness report $(\mathrm{c} / \mathrm{a}=4.89)$ [8]. From the results of Table I, we can say that the compound $\mathrm{Sc}_{2} \mathrm{SiN}$ is harder and more stable than $\mathrm{Sc}_{2} \mathrm{SiC}$ due to the high value of the compressibility modulus and it has minimum energy. We note that upon the substitution of $\mathrm{C}$ by $\mathrm{N}$, the values of $a$ and $c$ increased slightly, a consequence of the electronegativity of nitrogen being larger than that of carbon. The bulk modulus increases by $13.73 \%$ as the $\mathrm{C}$ is substituted with $\mathrm{N}$.

\subsection{Formation and cohesive energy}

To see the relative phase stabilities, we calculated the energy of formation for $\mathrm{Sc}_{2} \mathrm{Si} \mathrm{X}, \mathrm{X}=(\mathrm{C}, \mathrm{N})$ using [5,25]

$$
\mathrm{E}_{\mathrm{For}}^{\mathrm{Sc}_{2} \mathrm{SiC}}=\frac{\mathrm{E}_{\mathrm{Total}}^{\mathrm{Sc}_{2} \mathrm{CdC}}-\left(x \mathrm{E}_{\text {bulk }}^{\mathrm{Sc}}+y \mathrm{E}_{\text {bulk }}^{\mathrm{Si}}+z \mathrm{E}_{\text {bulk }}^{\mathrm{C}}\right)}{x+y+z},
$$

where $x, y$, and $z$ indicate a number of atoms in a unit cell, of $\mathrm{Sc}, \mathrm{Si}, \mathrm{N}$, and $\mathrm{C}$ atom in cell respectively. $\mathrm{E}_{\mathrm{For}}^{\mathrm{Sc}_{2} \mathrm{SiC}}, \mathrm{E}_{\mathrm{bulk}}^{\mathrm{Sc}}$, $\mathrm{E}_{\text {bulk }}^{\mathrm{Si}}, \mathrm{E}_{\text {bulk }}^{\mathrm{C}}, \mathrm{E}_{\text {bulk }}^{N}$ are the calculated total energies. During calculation, Scandium is a centered cubic (space group $\operatorname{Im} \overline{3} \mathrm{~m}$, prototype W) [26], Silicon crystallized in a face-centered cubic (space group $\mathrm{Fm} \overline{3}$ m,prototype $\mathrm{Cu}$ ) [27], Nitrogen crystallized in the hexagonal structure (P63/mmc prototype $\mathrm{C}$ graphite) [28], Carbon Crystallized in the diamond structure (spatial group $\mathrm{Fd} 3 \mathrm{~m}$ ), [29]. The calculation of the formation energy gives the interaction of the stability of the compound, giving a result of $-0.72 \mathrm{eV} /$ atom and $-3.6 \mathrm{eV} /$ atom for $\mathrm{Sc}_{2} \mathrm{SiC}$ and $\mathrm{Sc}_{2} \mathrm{SiN}$, respectively; these values are all negative, confirming that the structure of this phase can exist stably. Since the negative effects of the formation energy of $\mathrm{Sc}_{2} \mathrm{SiC}, \mathrm{Sc}_{2} \mathrm{SiN}$ rise progressively, we can say that the $\mathrm{Sc}_{2} \mathrm{SiN}$ configuration has a stronger capacity than the $\mathrm{Sc}_{2} \mathrm{SiC}$ configuration, (see Table I). The cohesive energy of a solid is the energy necessary to disassemble it into its constituent parts, that is to say, its binding energy. This energy depends, of course, on what is designated by the constituent parts. These are usually the individual atoms of the chemical elements that make up the solid, but other conventions are sometimes used. It may be practical to define cohesive energy as the energy required to separate atoms into an isolated set. To confirm the structural stability we have calculated the cohesive energy of each compound using Eq. (2) $[5,25,30]$.

$$
\mathrm{E}_{\mathrm{Coh}}^{\mathrm{Sc} \mathrm{SiC}_{2}}=\frac{\left(x \mathrm{E}_{\mathrm{Coh}}^{\mathrm{Sc}}+y \mathrm{E}_{\mathrm{Coh}}^{\mathrm{Si}}+z \mathrm{E}_{\mathrm{Coh}}^{\mathrm{C}}\right)-\mathrm{E}_{\mathrm{Total}}^{\mathrm{Sc}_{2} \mathrm{SiC}_{1}}}{x+y+z} .
$$



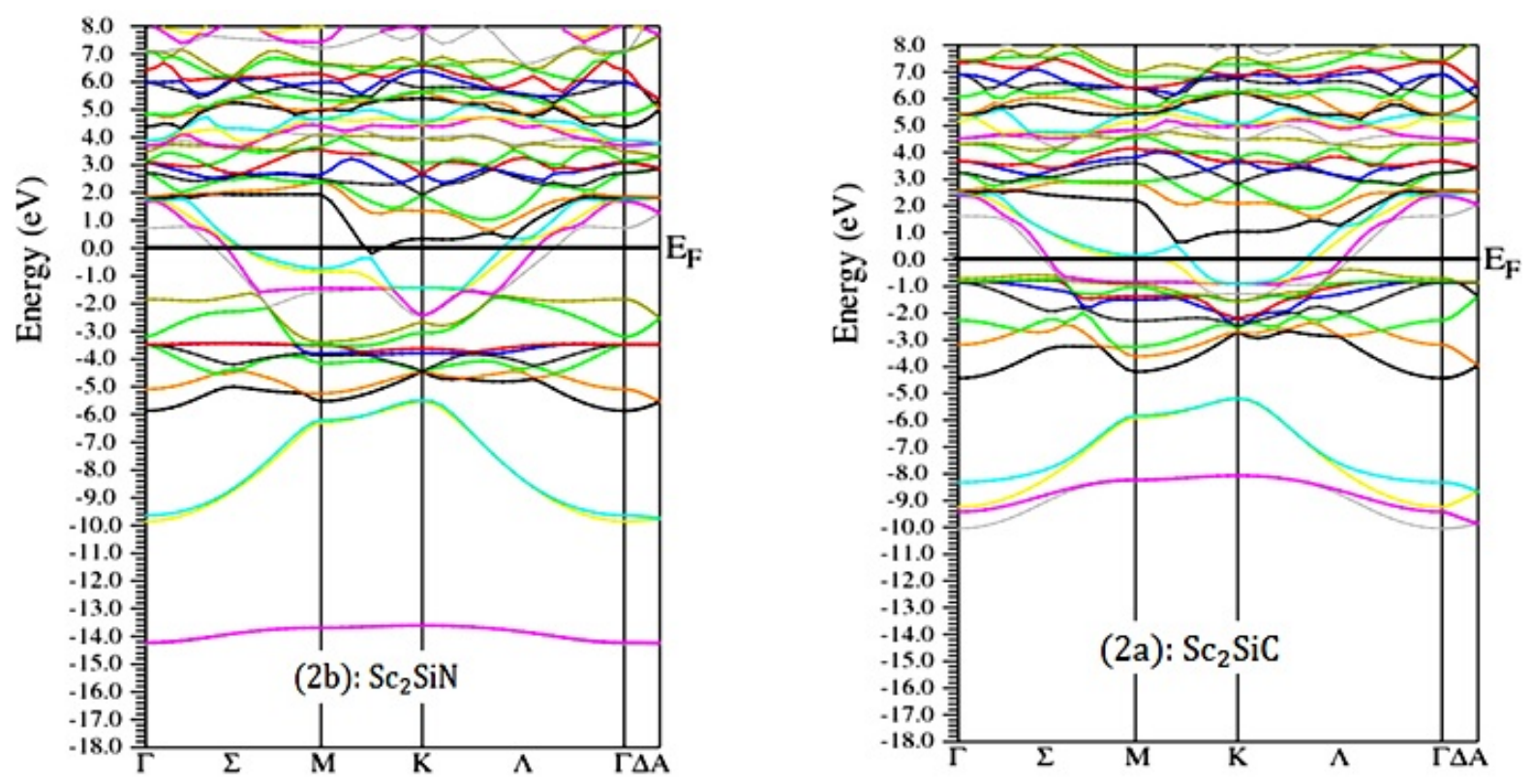

FIGURE 2. Calculated band structure of a) $\mathrm{Sc}_{2} \mathrm{SiC}$ and b) $\mathrm{Sc}_{2} \mathrm{SiN}$ with LDA approximation along the high symmetry directions in the Brillouin zone at ambient conditions.
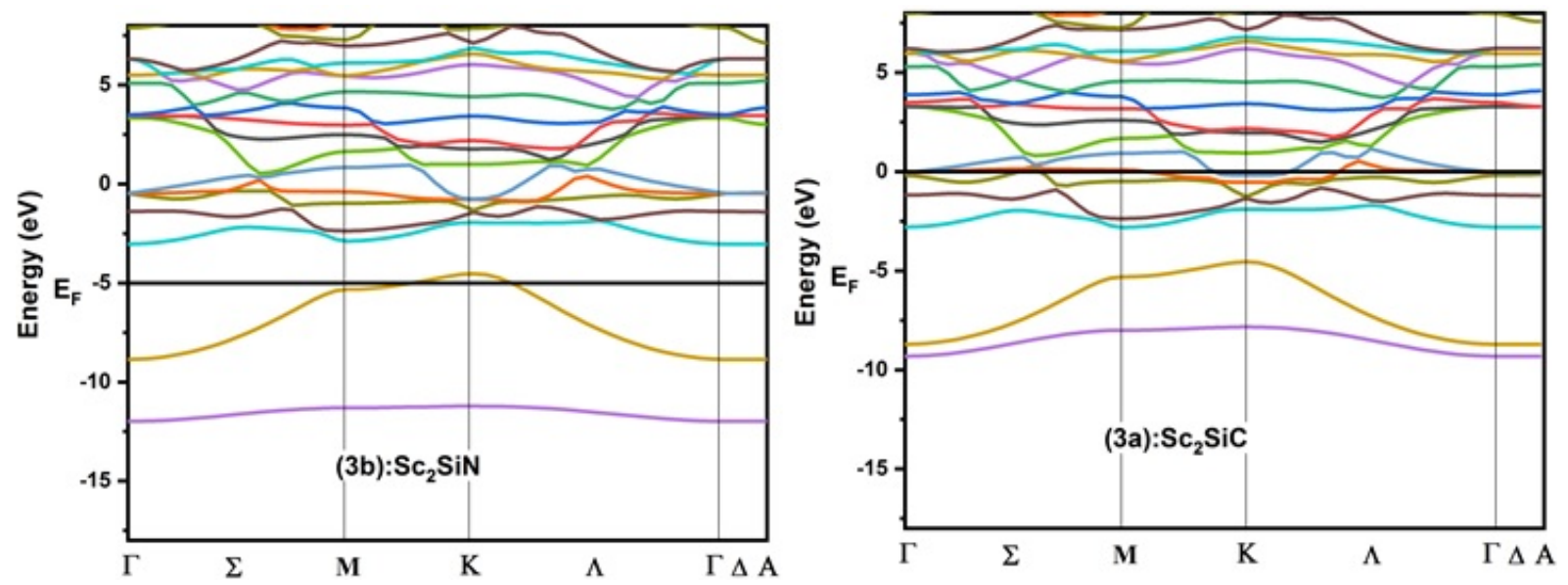

FIgURE 3. Calculated band structure of a) $\mathrm{Sc}_{2} \mathrm{SiC}$ and b) $\mathrm{Sc}_{2} \mathrm{SiN}$ with GGA approximation along the high symmetry directions in the Brillouin zone at ambient conditions.

where $\mathrm{E}_{\mathrm{Coh}}^{\mathrm{Sc}_{2} \mathrm{SiC}}$ is the overall energy of the unit cell used in the present calculation, $x, y$, and $z$ are the numbers of Sc, $\mathrm{Si}, \mathrm{C}$ atom in unit cell, respectively, $\mathrm{E}_{\mathrm{Coh}}^{\mathrm{Sc}_{2} \mathrm{SiC}}$ refers to the total energy of type $\mathrm{Sc}_{2} \mathrm{SiC}$ in the equilibrium configuration, and $\mathrm{E}_{\mathrm{Coh}}^{\mathrm{Sc}}, \mathrm{E}_{\mathrm{Coh}}^{\mathrm{Si}}, \mathrm{E}_{\mathrm{Coh}}^{\mathrm{C}}, \mathrm{E}_{\mathrm{Coh}}^{\mathrm{N}}$ are the isolated atomic energies of the pure constituents [25]. The calculation of the cohesive energy is posted in Table I. The computed cohesive energies are $7.07 \mathrm{eV} /$ atom and $4.98 \mathrm{eV} /$ atom for $\mathrm{Sc}_{2} \mathrm{SiC}$ and $\mathrm{Sc}_{2} \mathrm{SiN}$, respectively. From this result, it can be said that the $\mathrm{Sc}_{2} \mathrm{SiN}$ compound is more stable than the $\mathrm{Sc}_{2} \mathrm{SiC}$ compound due to the lower value of the cohesive energy.

\subsection{Electronic properties}

\subsubsection{Band structures}

We calculated the electronic band structures of $\mathrm{Sc}_{2} \mathrm{SiC}$ and $\mathrm{Sc}_{2} \mathrm{SiN}$ at equilibrium lattice parameters along with the high symmetry directions in the first Brillouin zone, with LDA, GGA, and GGA+TB-mBJ, which are presented in Fig. 2, 3, and 4 , respectively. The conduction bands are shifted towards the valence bands and overlap significantly at the Fermi level, and the absence of a gap for the two compounds clearly indicates the metallic character. The states with energies below minus $-10 \mathrm{eV},-14 \mathrm{eV}$ below the Fermi level provided $(\mathrm{C}, \mathrm{N})$ 

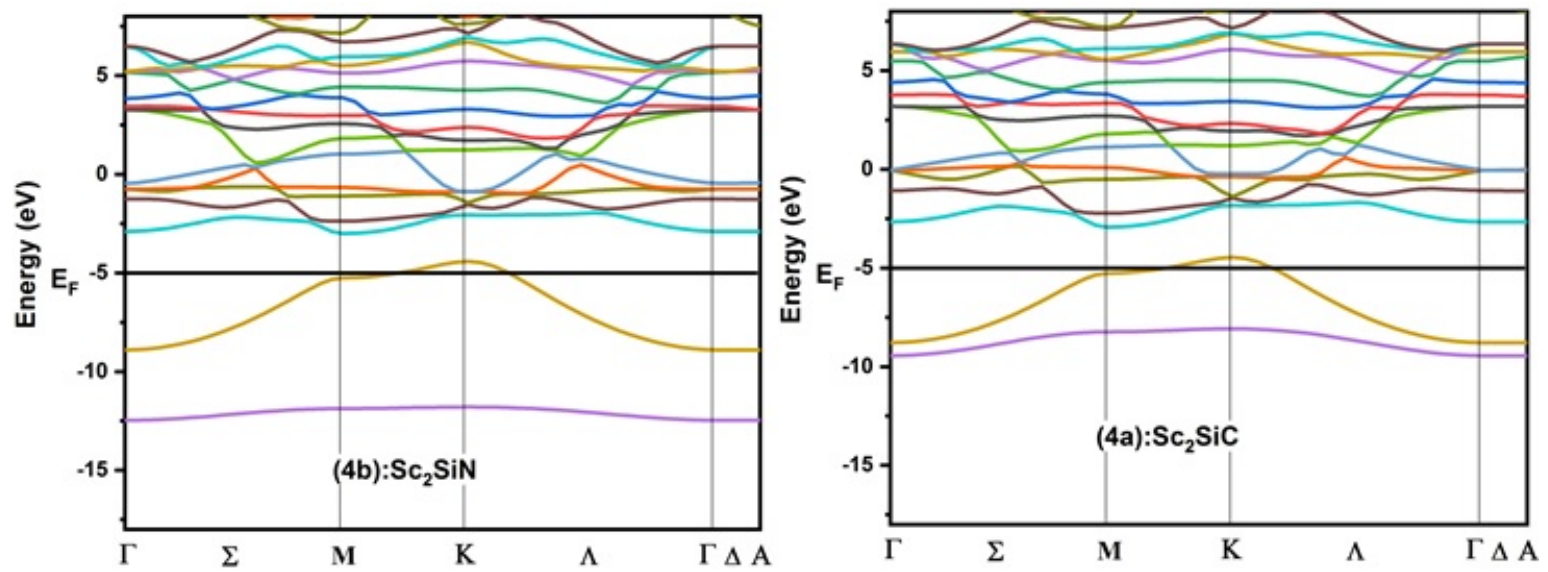

FIGURE 4. Calculated band structure of a) $\mathrm{Sc}_{2} \mathrm{SiC}$ and b) $\mathrm{Sc}_{2} \mathrm{SiN}$ with GGA+TB-mBJ approximation along the high symmetry directions in the Brillouin zone at ambient conditions.
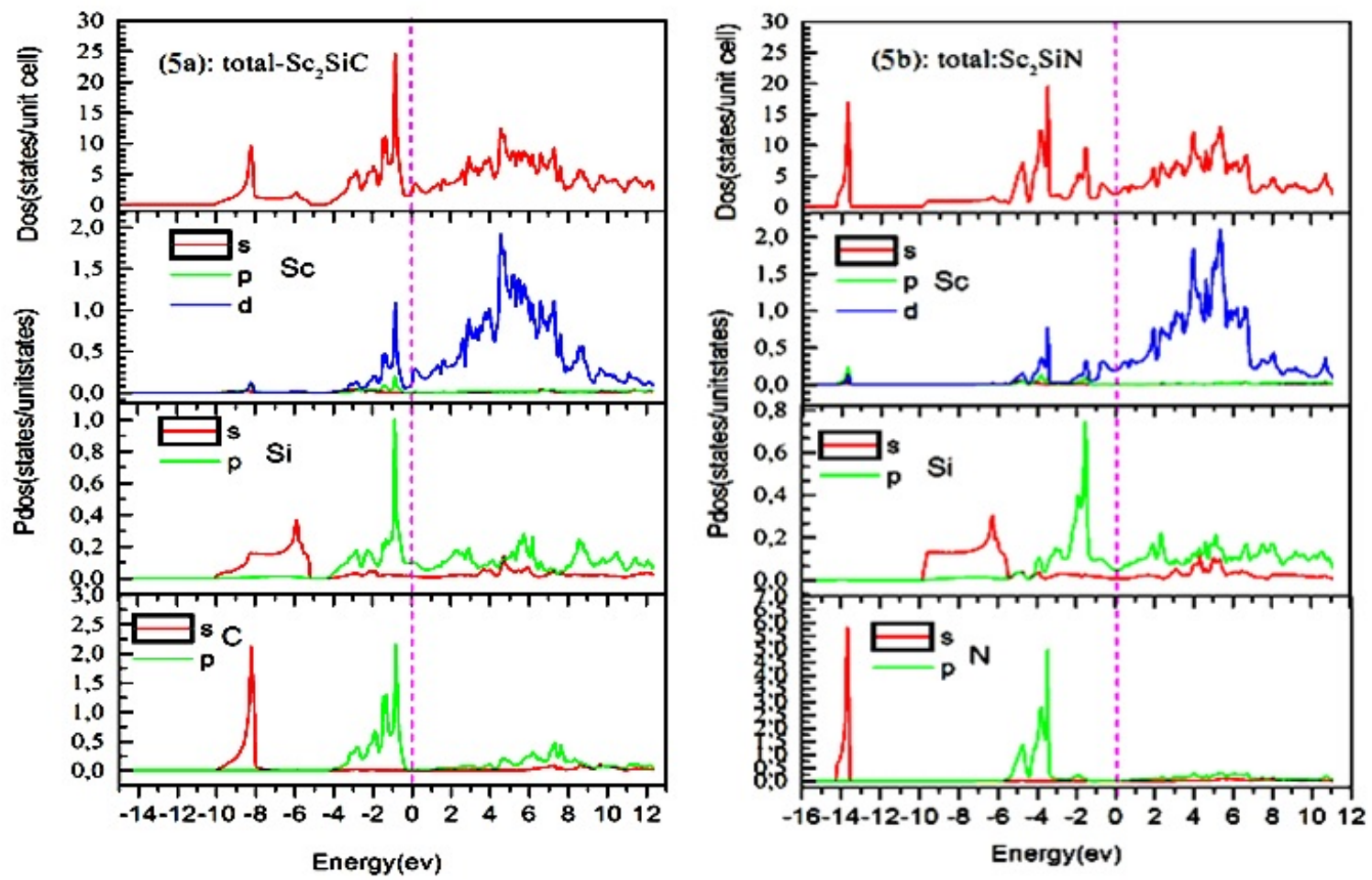

FIgURE 5. Total and partial densities of states of a) $\mathrm{Sc}_{2} \mathrm{SiC}$ and b) $\mathrm{Sc}_{2} \mathrm{SiN}$.

-2s states respectively, the states just at the Fermi level were mainly Sc-3d states, $(\mathrm{C}, \mathrm{N})-2 \mathrm{p}$ and $\mathrm{Si}-3 \mathrm{~s}$ and $3 \mathrm{p}$. This result confirms the metallicity of these two materials.

\subsubsection{Densities of states}

We have calculated the total and partial density of states (DOS) presented in Fig. 5a, 5b. We see that there is no band gap $E_{g}$ at the Fermi level for the two materials, which allows us to deduce that these two compounds have a metallic bonding nature since the DOS has a large finite value at the Fermi level. Thus, the broad values of the Fermi energies
$\left(\mathrm{E}_{F}\right)$ (see Table II) confirm this result. At the level of Fermi, the DOS is 2.025 and 1.695 states per unit cell per eV for $\mathrm{Sc}_{2} \mathrm{SiC}$ and $\mathrm{Sc}_{2} \mathrm{SiN}$ respectively. It can be concluded that $\mathrm{Sc}_{2} \mathrm{SiN}$ is more conductive than $\mathrm{Sc}_{2} \mathrm{SiC}$. On the other hand, Sc-3d electrons play the dominant role in DOS, which primarily contributes to DOS at the Fermi level and should be involved in the conduction properties. Although 3d electrons are generally considered as low-efficiency drivers. The C-2p and $\mathrm{Si}-3 \mathrm{p}$ electrons do not significantly contribute to DOS at the Fermi level and are therefore not involved in the conduction properties. The partial DOS profiles in Fig. 5a, 5b show 

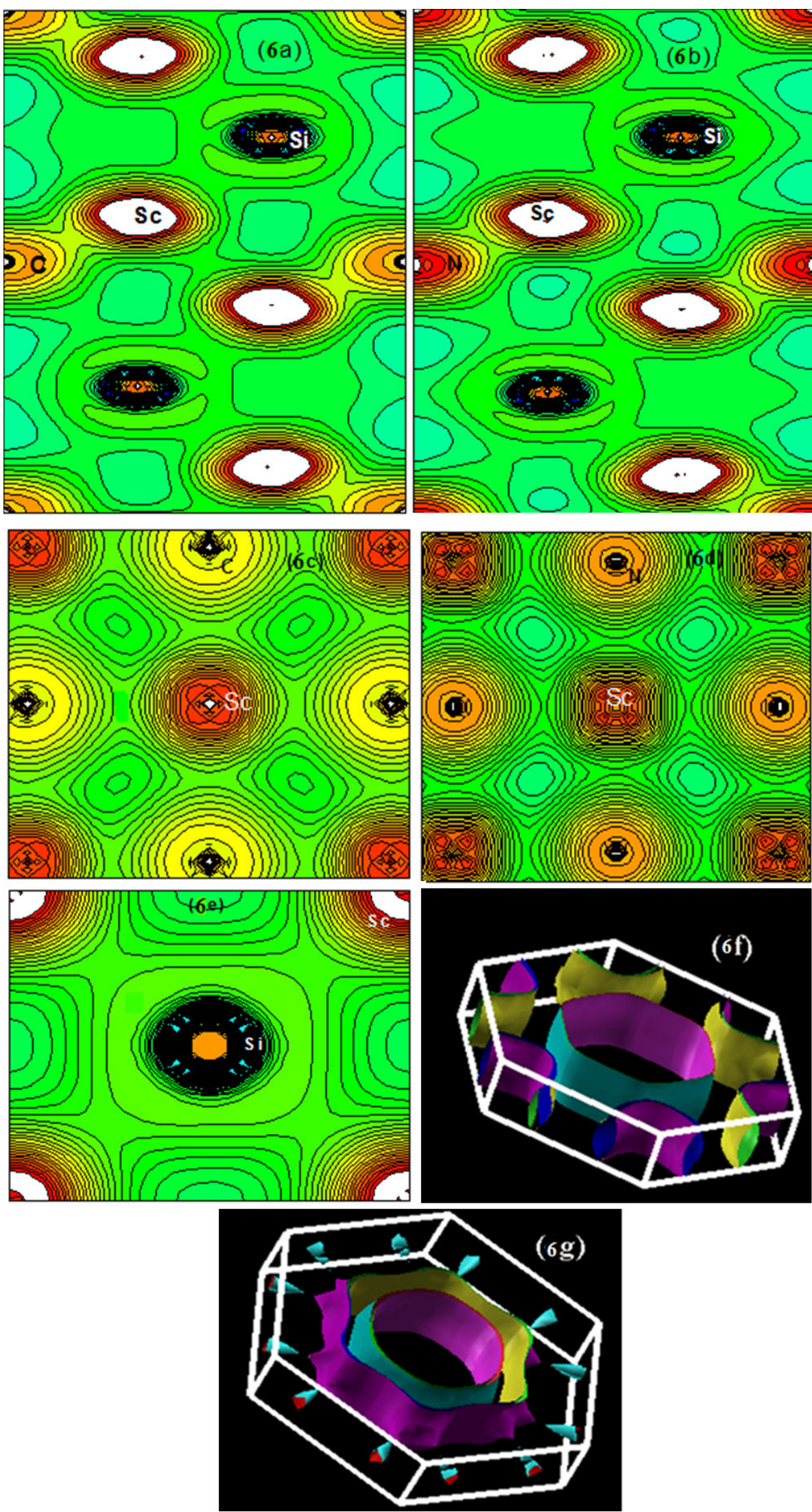

FIGURE 6. Electronic charge density maps of a) $\mathrm{Sc}_{2} \mathrm{SiC}$ and b) $\mathrm{Sc}_{2} \mathrm{SiN}$ phases and binary c) $\mathrm{ScC}$, d) $\mathrm{ScN}$, e) $\mathrm{ScSi}$. The Fermi surfaces of the two phases $\mathrm{Sc}_{2} \mathrm{SiC}$ and $\mathrm{Sc}_{2} \mathrm{SiN}$ are plotted in $\mathrm{f}$ ) and $\mathrm{g}$ ), respectively. 
TABLE II. The calculated values of the energy of formation $\left(E_{\mathrm{For}}\right)$, bulk modulus $\left(\mathrm{B}_{0}\right)$, cohesive energies $\left(\mathrm{E}_{\mathrm{Coh}}\right)$,) and the valence electron concentration (val-el) for $\mathrm{Sc}_{2} \mathrm{SiX}(\mathrm{X}=\mathrm{C}, \mathrm{N})$.

\begin{tabular}{ccc}
\hline & $\mathrm{Sc}_{2} \mathrm{SiC}$ & $\mathrm{Sc}_{2} \mathrm{SiN}$ \\
\hline $\mathrm{E}_{\mathrm{Eq}}$ & -7407.880848 & -7474.654553 \\
$\mathrm{E}_{\mathrm{For}(\mathrm{eV} / \text { atom })}$ & -0.72 & -3.6 \\
$\mathrm{E}_{\mathrm{Coh}(\mathrm{eVatom})}$ & 7.07 & 4.98 \\
valence electron & 60 & 62 \\
$\mathrm{~B}_{0}(\mathrm{Gpa})$ & 130.7 & 151.5 \\
$\mathrm{E}_{\mathrm{F}}$ & 0.51 & 0.60 \\
\hline
\end{tabular}

another interesting feature: the hybridization peak is strongly dominated by the contribution of the (C, N) 2 -p, Sc-3d states, but there is weak hybridization of the $\mathrm{Si}-3 \mathrm{p}$ and $\mathrm{Sc}-3 \mathrm{~d}$ states; this would be beneficial to the structural stability of $\mathrm{Sc}_{2} \mathrm{SiN}$. The main difference is that the electrostatic attraction of nitrogen is higher than that of carbon, and the electrical conductivity of $\mathrm{Sc}_{2} \mathrm{SiN}$ is greater than that of $\mathrm{Sc}_{2} \mathrm{SiC}$. It can be concluded that the Sc-3d, $\mathrm{Si}-3 \mathrm{p}$ bonds are stronger in $\mathrm{Sc}_{2} \mathrm{SiN}$ than in $\mathrm{Sc}_{2} \mathrm{SiC}$.

\subsubsection{Charge densities and Fermi surface}

As a rule of thumb, the nature of the chemical bond is related to the difference in electronegativity between the elements at play, as it informs us about the charge transfer and, consequently, on the nature of the bond in the materials. The MAX phases are generally stacks of a "hard" M-X bond and a "soft" M-A bond in the $c$ direction. The Ti-C bond strength is much stronger than the $\mathrm{Ti}-\mathrm{Al}$ bond in $\mathrm{Ti}_{2} \mathrm{AlC}$ [31]. Figures $6 \mathrm{a}$ and $6 \mathrm{~b}$ show the contours of the charge densities of $\mathrm{Sc}_{2} \mathrm{Si} \mathrm{X}(\mathrm{X}=\mathrm{C}, \mathrm{N})$ in the $(11 \overline{2} 0)$ plane, and the density contours for ScX binary compounds (X: C, N), Figs. 6c, 6d, in the plane (100), where the last two phases crystallize in the $\mathrm{NaCl}$ structure with the (space group $\mathrm{Fm} \overline{3} \mathrm{~m}$ ), and $\mathrm{ScSi}$ binary compound crystallized in the cubic structure $(\mathrm{F} \overline{4} 3 \mathrm{~m}$ space group), Fig. 6e. The interaction of $\mathrm{Sc}-\mathrm{C}$ in $\mathrm{Sc}_{2} \mathrm{Si} \mathrm{C}$ is covalent in nature and is very strong. At the same time, the more electronegative nature of $\mathrm{C}$ compared to Sc confirms the presence of the ionic bond between $\mathrm{Sc}$ and $\mathrm{C}$, as seen in Fig. 6a, while the more electropositive nature of Si confirms the ionic bond between $\mathrm{Sc}$ and $\mathrm{Si}$ (see Fig. 6e). Therefore, the chemical bond in $\mathrm{Sc}_{2} \mathrm{Si} \mathrm{C}$ is metallic, covalent, and ionic in nature. Covalent behavior is due to local interactions $(\mathrm{Sc}, \mathrm{Si}$ ) of hybridization states and $\mathrm{C}-2 \mathrm{p}$ states. Furthermore, the chemical bond in $\mathrm{Sc}_{2} \mathrm{Si} \mathrm{C}$ is anisotropic with the metal bond in the $\mathrm{Sc}$ and $\mathrm{Si}$ layers which are parallel to the basal plane Fig. 6e, while, there are strong directional covalent and ionic bonds between the $\mathrm{Sc}-\mathrm{C}$ atoms and $\mathrm{Sc}-\mathrm{Si}$. This strong anisotropy of the chemical bond is linked to the physical and mechanical properties of the materials laid; high melting points and large modulus of compressibility are expected from the strong covalent and ionic bond, while good electrical conductivity and plasticity are expected from the existence of the metal bond. Therefore, $\mathrm{Sc}_{2} \mathrm{Si} \mathrm{N}$ demonstrates anisotropic chemical binding similar to $\mathrm{Sc}_{2} \mathrm{Si} \mathrm{C}$. The chemical bond is covalent metallic-ionic in nature, with more contribution from ionic and metallic bonds, which result in anisotropic properties in $\mathrm{Sc}_{2} \mathrm{Si} \mathrm{N}$. It can be concluded by analyzing the M-X bonds in $\mathrm{ScC}$ and the $\mathrm{ScN}$-depicted in Figs. $6 \mathrm{c}$ and $6 \mathrm{~d}-$ that the bond is characterized by a covalent and ionic contribution, and this character is essentially retained in the ternary compound $\mathrm{Sc}_{2} \mathrm{Si} \mathrm{X}$. In fact, the metallic bond between $\mathrm{Sc}$ and $\mathrm{Si}$ in $\mathrm{Sc}_{2} \mathrm{Si} \mathrm{X}$ is also similar to the bond in $\mathrm{ScSi}$. Finally, we also notice that by replacing $\mathrm{C}$ with $\mathrm{N}$, the uniform region of charge density between MX layers is extended, which may be responsible for the large compressibility modulus, as discussed above of $\mathrm{Sc}_{2} \mathrm{Si}$ N. Figures $6 \mathrm{f}, 6 \mathrm{~g}$ represent the Fermi surface topology of the $\mathrm{Sc}_{2} \mathrm{SiX}(\mathrm{X}=\mathrm{C}$, $\mathrm{N})$ compounds. It can be said that for the $\mathrm{Sc}_{2} \mathrm{SiC}$ material, the center of the Fermi surface consists of a closed central sheet with additional sheets appearing at the corners of the Brillouin zone. For the material $\mathrm{Sc}_{2} \mathrm{SiN}$, the shape of the Fermi surface is different from that of $\mathrm{Sc}_{2} \mathrm{SiC}$, where the center of the Fermi surface is composed of several layers: the first is of cylindrical type and the last one adopts a prismatic shape. So the Fermi surface of the $\mathrm{Sc}_{2} \mathrm{SiX}$ compounds $(\mathrm{X}=\mathrm{C}, \mathrm{N})$ are due to the low diffusion of the Sc-3d and Si-5p states as shown in the bottom of Fig. 5.

\subsection{Elastic properties and mechanical stability}

The calculation of the elastic constants will make it possible to examine the mechanical stability of the ground state proposed by the FP-LAPW method. The elastic behavior of a hexagonal system is described by five independent constants $\mathrm{C}_{11}, \mathrm{C}_{33}, \mathrm{C}_{44}, \mathrm{C}_{12}$, and $\mathrm{C}_{13}$ and the sixth constant $\mathrm{C}_{66}$ is calculated from $\mathrm{C}_{11}, \mathrm{C}_{12}$ [9]. These constants can be determined from a change of total energy as a function of the constraint. The evaluation of elastic constants was made from deformation formulas proposed by Wallace. We also find that the elastic constants of the different phases satisfy the following relation [11,32].

$$
\begin{aligned}
& \mathrm{C}_{11}>0, \quad\left(\mathrm{C}_{11}-\mathrm{C}_{12}\right)>0, \quad \text { and } \\
& \left(\mathrm{C}_{11}+\mathrm{C}_{12}\right) \mathrm{C}_{33}>2 \mathrm{C}_{13}^{2} .
\end{aligned}
$$

Calculations of second-order elastic constants of $\mathrm{Sc}_{2} \mathrm{Si}$ $\mathrm{X}, \mathrm{X}=(\mathrm{C}, \mathrm{N})$ are presented in Table III. It can be said that the compounds $\mathrm{Sc}_{2} \mathrm{Si} X, \mathrm{X}=(\mathrm{C}, \mathrm{N})$, are mechanically stable because all these elastic constants are positive and meet the criterion of mechanical stability [11] on top of the fact that all the elastic constants increase when $\mathrm{C}$ is replaced by $\mathrm{N}$. Thus, it can be concluded that the $\mathrm{Sc}-\mathrm{N}$ bonds are stronger than

\begin{tabular}{cccccccc}
\hline \multicolumn{6}{l}{ TABLE III. Elastic constant $\mathrm{C}_{i j}$ for $\mathrm{Sc}_{2} \mathrm{SiX}(\mathrm{X}=\mathrm{C}, \mathrm{N})}$. \\
\hline & $\mathrm{C}_{11}$ & $\mathrm{C}_{12}$ & $\mathrm{C}_{13}$ & $\mathrm{C}_{33}$ & $\mathrm{C}_{44}$ & $\mathrm{C}_{66}$ & $\mathrm{~B} / \mathrm{C}_{44}$ \\
\hline $\mathrm{Sc}_{2} \mathrm{SiC}$ & 224.62 & 77.3 & 73.67 & 309.86 & 100.92 & 73.66 & 1.32 \\
$\mathrm{Sc}_{2} \mathrm{SiN}$ & 263.68 & 75.14 & 87.92 & 330.43 & 127.47 & 94.27 & 1.18 \\
\hline
\end{tabular}


TABLE IV. The bulk modulus B, shear modulus G, Young's modulus E (all in GPa), Poisson's ratio $v$, anisotropic factor A, linear compressibility ratio $f=K_{c} / K_{a}$ for $\mathrm{Sc}_{2} \mathrm{SiX}(\mathrm{X}=\mathrm{C}, \mathrm{N})$.

\begin{tabular}{|c|c|c|c|c|c|c|c|c|c|}
\hline & E & B & $\mathrm{G}$ & $\mathrm{A}_{1}$ & $\mathrm{~A}_{2}$ & $\mathrm{~A}_{3}$ & $v$ & $\mathrm{f}$ & G/B \\
\hline $\mathrm{Sc}_{2} \mathrm{~S}$ & 219.23 & 133.09 & 89.45 & 1.04 & 1.37 & 1.4 & 0.22 & 0.65 & 0.67 \\
\hline $\mathrm{Sc}_{2} \mathrm{SiN}$ & 263.52 & 149.99 & 109.14 & 0.85 & 1.35 & 1.15 & 0.207 & 0.67 & 0.73 \\
\hline
\end{tabular}

the Sc-C bonds. The modules $\mathrm{C}_{i j}$ have a heavyweight in the study of materials, especially module $\mathrm{C}_{44}$. From this quantity, several properties can be determined such as brittleness, ductility, among others. The two constants $\mathrm{C}_{11}$ and $\mathrm{C}_{33}$ are connected to the directions $a$ and $c$, respectively, while $\mathrm{C}_{44}$ is related to the shear constraint. The module of $\mathrm{C}_{44}$ shows that $\mathrm{Sc}_{2} \mathrm{SiN}$ is harder than $\mathrm{Sc}_{2} \mathrm{SiC}$, a result that is similar to that found in the optimization part.

The modulus B, the shear modulus G, Young's The modulus E, the Poisson ratio for $\mathrm{Sc}_{2} \mathrm{SiX}, \mathrm{X}=(\mathrm{C}, \mathrm{N})$, get from the individual elastic constants by the Hill approximation, this approximation is based on the approaches of Reuss and Voigt are given In Table IV, with $\mathrm{B}=\left(\mathrm{B}_{V}+\mathrm{B}_{R}\right)=\mathrm{B}_{H}$ (Hill'sbulk modulus) and $\mathrm{G}=\left(\mathrm{G}_{V}+\mathrm{G}_{R}\right)=\mathrm{G}_{H}$ (Hill's shear) [31,32]. The Young's modulus $\mathrm{E}$ and the Poisson's ratio $v$ are determined by the relations $\mathrm{E}=9 \mathrm{BG} /(3 \mathrm{~B}+\mathrm{G})$ and $v=(3 B-E) / 6 B$ $[33,34]$, where the bulk modulus $B$ determines the resustance of a material to change its volume and characterizes the response to hydrostatic pressure. The shear modulus $\mathrm{G}$ represents the resistance of a material to change shape and Young's modulus determines the resitance against uniaxial tensions. These are important parameters for defining the mechanical properties of a material [35]. These results are presented in (Table IV) and reveal that the compressibility modulus, shear modulus, and Young modulus for $\mathrm{Sc}_{2} \mathrm{Si} X, \mathrm{X}=(\mathrm{C}, \mathrm{N})$, are between the maximum and minimum possible values of these modules for the phases 211 MAX described in Refs. [9,6]. We see that all the modules increase (B, G, E, $v$ ) when $\mathrm{C}$ is replaced by $\mathrm{N}$. We conclude that

- The $\mathrm{Sc}_{2} \mathrm{SiN}$ compound is stiffer and harder than $\mathrm{Sc}_{2} \mathrm{SiC}$ due to the high value of the Young's modulus and compressibility modulus.

- From the Pugh Criterions [37], a material must behave ductile if $\mu_{D}=G / B<0.5$ and fragile otherwise. In our calculation, $\mu_{D}\left(\mathrm{Sc}_{2} \mathrm{SiC}\right)=0.67$ and $\mu_{D}\left(\mathrm{Sc}_{2} \mathrm{SiN}\right)=0.73$ are almost equal, implying that $\mathrm{Sc}_{2} \mathrm{SiC}$ and $\mathrm{Sc}_{2} \mathrm{SiN}$ behave like fragile materials.

- An additional point for the brittle/ductile conduct of this phase results from the evaluated Poisson's ratio. According to Frantsevich et al. [38], metals with a Poisson's ratio of about $1 / 3$ are ductile, whereas metals with a Poisson's ratio of less than $1 / 3$ are deduced to be fragile; the values for $\mathrm{Sc}_{2} \mathrm{SiC}_{\mathrm{C}}$ and $\mathrm{Sc}_{2} \mathrm{SiN}$ are 0.22 and 0.23 , respectively.
- Another useful factor is the machinability index $\mu_{\mathrm{M}=\mathrm{B}} / \mathrm{C}_{44}[33,39]$. In our calculation, $\mu_{\mathrm{M}}\left(\mathrm{Sc}_{2} \mathrm{SiC}\right)=$ 1.32 and $\mu_{\mathrm{M}}\left(\mathrm{Sc}_{2} \mathrm{SiN}\right)=1.27$, values which are greater than $\mu_{\mathrm{M}}\left(\mathrm{Ti}_{2} \mathrm{AlC}\right)=1.23$ [18], but much less that for the 211 MAX phases with the greatest machinability: $\mu_{\mathrm{M}}\left(\mathrm{W}_{2} \mathrm{SnC}\right)=33.3$ and $\mu_{\mathrm{M}}\left(\mathrm{Mo}_{2} \mathrm{PbC}\right)=15.8$ [12].

- We have determined the elastic anisotropy factors, $A_{1}$, $A_{2}$ and $A_{3}$ for the hexagonal crystal determined by the ratio between the linear compressibility coefficients along with the $a$ - and $c$-axis. There are three independent elastic shear constants for hexagonal crystals; thus, three shear-type anisotropy factors can be determined by [11]

$$
\begin{aligned}
& A_{1}=\frac{1 / 6\left(\mathrm{C}_{11}+\mathrm{C}_{12}+2 \mathrm{C}_{33}-4 \mathrm{C}_{13}\right)}{\mathrm{C}_{44}}, \\
& A_{2}=\frac{2 \mathrm{C}_{44}}{\mathrm{C}_{11}-\mathrm{C}_{12}}, \\
& A_{3}=A_{1} \cdot A_{2}=\frac{1 / 3\left(\mathrm{C}_{11}+\mathrm{C}_{12}+2 \mathrm{C}_{33}-4 \mathrm{C}_{13}\right)}{\mathrm{C}_{11}-\mathrm{C}_{12}} .
\end{aligned}
$$

These anisotropy factors are presented in Table IV, and any deviation of more than or less than 1 corresponds to an elastic anisotropy. The magnitude of the deviation from 1 is a measure of the degree of elastic anisotropy possessed by the crystal [18]. Finally, the ratio between the linear coefficients of compressibility $f=K_{c} / K_{a}$ of the hexagonal crystals with the $a$ - and $c$-axis, it is defined [11,12] $f=K_{c} / K_{a}=\left(\mathrm{C}_{11}+\mathrm{C}_{12}-2 \mathrm{C}_{13}\right) /\left(\mathrm{C}_{33}-\mathrm{C}_{13}\right)$.

The results show that for $\mathrm{Sc}_{2} \mathrm{SiC}$ and $\mathrm{Sc}_{2} \mathrm{SiN}, f=$ $(0.65,0.67)$, respectively. Furthermore, since these values of $f$ are less than 1 , the compressibility along the $c$-axis is smaller than alogn the $a$ - axis for both compounds. For comparison, this parameter for the isoelectronic $\mathrm{Nb}_{2} \mathrm{SnC}$ compound is $f=0.94$, i.e., it lies close to the isotropic limit $f=1[12,33,40]$.

\section{Conclusion}

In summary, using the augmented planar wave (FP-LAPW) method, based on the DFT, within the LDA, GGA, and GGA+TB-mBj. We studied the structural, electronic, and elastic properties of $\mathrm{Sc}_{2} \mathrm{SiC}, \mathrm{Sc}_{2} \mathrm{SiN}$ compounds. Our results show that the substitution of $\mathrm{C}$ by $\mathrm{N}$ in $\mathrm{Sc}_{2} \mathrm{SiC}$ affects the structural, elastic, and electronic properties of the material. We calculated both formation energies of the carbon-based and the nitrogen-based compounds, which allow us to conclude that the synthesis of these two compounds can be realized. The state $\mathrm{Sc}-3 \mathrm{~d}$ and $\mathrm{C}-2 \mathrm{p}$ are stronger than the state Sc-3d and Si-3p. Sc $\mathrm{Sc}_{2} \mathrm{SiX}, \mathrm{X}=\mathrm{C}, \mathrm{N}$, has a metallic-covalentionic character in nature. Fermi's surface properties were studied for the first time, and the replacement of $\mathrm{N}$ by $\mathrm{C}$ increases all elastic constants. The elastic anisotropy of $\mathrm{Sc}_{2} \mathrm{SiN}$ is higher than that of $\mathrm{Sc}_{2} \mathrm{SiC}$. 
1. V. H. Nowotny, Strukturchemie einiger Verbindungen der Übergangsmetalle mit den elementen C, Si, Ge, Sn, Prog. Solid State Chem. 5 (1971) 27, https://doi.org/10.1016/ 0079-6786(71) 90016-1.

2. P. Eklund et al., The $\mathrm{M}_{n+1} \mathrm{AX}_{n}$ phases: Materials science and thin-film processing, Thin Solid Films 518 (2010) 1851, https://doi.org/10.1016/j.tsf.2009.07.184

3. J. M. Schneider, D. Music and Z. Sun, (2005) . (reference is incomplete)

4. M. W. Barsoum, The $\mathrm{M}_{N+1} \mathrm{AX}_{N}$ phases: A new class of solids: Thermodynamically stable nanolaminates, Prog. Solid State Chem. 28 (2000) 201, https : / / doi.org/10. 1016/S0079-6786(00)00006-6

5. M. Mebrek et al., A Novel Theoretical Study of Elastic and Electronic Properties of $\mathrm{M}_{2} \mathrm{CdC}(\mathrm{M}=\mathrm{Zr}$, Hf, and Ta) MAX Phases, Acta Phys. Pol. A 133 (2018) 76, https://doi. org/10.12693/APhysPolA.131.76

6. A. Bouhemadou, Structural and elastic properties under pressure effect of $\mathrm{Hf}_{2} \mathrm{AlN}$ and $\mathrm{Hf}_{2} \mathrm{AlC}$, High Press. Res. 28 (2008) 45, https://doi.org/10.1080/ 08957950701882872

7. G. Hug and E. Fries, Full-potential electronic structure of $\mathrm{Ti}_{2} \mathrm{AlC}$ and $\mathrm{Ti}_{2} \mathrm{AlN}$, Phys. Rev. B 65 (2002) 113104, https : //doi.org/10.1103/PhysRevB.65.113104

8. G. Hug, M. Jaouen, and M. W. Barsoum, X-ray absorption spectroscopy, EELS, and full-potential augmented plane wave study of the electronic structure of $\mathrm{Ti}_{2} \mathrm{AlC}, \mathrm{Ti}_{2} \mathrm{AlN}$, $\mathrm{Nb}_{2} \mathrm{AlC}$, and $\left(\mathrm{Ti}_{0.5} \mathrm{Nb}_{0.5}\right)_{2} \mathrm{AlC}$, Phys. Rev. B 71 (2005) 024105, https://doi.org/10.1103/PhysRevB. 71. 024105 .

9. A. Bouhemadou, Calculated structural, electronic and elastic properties of $\mathrm{M}_{2} \mathrm{GeC}(\mathrm{M}=\mathrm{Ti}, \mathrm{V}, \mathrm{Cr}, \mathrm{Zr}, \mathrm{Nb}, \mathrm{Mo}, \mathrm{Hf}$, Ta and W), Appl. Phys. A 96 (2009) 959, https://doi.org/10. 1007/s00339-009-5106-5

10. H. Wu et al., First-principles study of the structural, electronic and elastic properties of ternary $\mathrm{Zr}_{2} \mathrm{AN}(\mathrm{A}=\mathrm{Ga}$, In and $\mathrm{Tl}$ ), Comput. Mater. Sci. 84 (2014) 103, https://doi.org/ $10.1016 / j . c o m m a t s c i .2013 .11 .040$

11. M. A. Ali et al., Newly synthesized $\mathrm{Zr}_{2} \mathrm{AlC}$, $\mathrm{Zr}_{2}\left(\mathrm{Al}_{0.58} \mathrm{Bi}_{0.42}\right) \mathrm{C}, \mathrm{Zr}_{2}\left(\mathrm{Al}_{0.2} \mathrm{Sn}_{0.8}\right) \mathrm{C}$, and $\mathrm{Zr}_{2}\left(\mathrm{Al}_{0.3} \mathrm{Sb}_{0.7}\right) \mathrm{C}$ MAX phases: A DFT based first-principles study, Comput. Mater. Sci. 131 (2017) 139, https://doi.org/10. 1016/j.commatsci.2017.01.048

12. I. R. Shein and A. L. Ivanovskii, Structural, elastic, and electronic properties of new $211 \mathrm{MAX}$ phase $\mathrm{Nb}_{2} \mathrm{GeC}$ from firstprinciples calculations, Physica B 410 (2013) 42, https: //doi.org/10.1016/j.physb.2012.10.036

13. M. W. Barsoum and T. El-Raghy, Synthesis and Characterization of a Remarkable Ceramic: $\mathrm{Ti}_{3} \mathrm{SiC}_{2}, J$. Am. Ceram. Soc. 79 (1996) 1953, https://doi.org/10.1111/j. 1151-2916.1996.tb08018.x

14. J. M. Schneider, R. Mertens, and D. Music, Structure of $\mathrm{V}_{2} \mathrm{AlC}$ studied by theory and experiment, J. Appl. Phys. 99 (2006) 013501, https://doi.org/10.1063/1.2150601
15. I. Kero, R. Tegman, and M.-L. Antii, Phase reactions associated with the formation of $\mathrm{Ti}_{3} \mathrm{SiC}_{2}$ from TiC/Si powders, $C e$ ram. Int. 37 (2011) 2615, https://doi.org/10.1016/ j.ceramint.2011.04.132

16. T. El-Raghy and M. W. Barsoum, Processing and Mechanical Properties of $\mathrm{Ti}_{3} \mathrm{SiC}_{2}$ : I, Reaction Path and Microstructure Evolution, J. Am. Ceram. Soc. 82 (1999) 2849, https://doi.org/10.1111/j.1151-2916.1999. tb02166.x

17. Z. Sun, Y. Zhou, and M. Li, Oxidation behaviour of $\mathrm{Ti}_{3} \mathrm{SiC}_{2}$-based ceramic at $900-1300^{\circ} \mathrm{C}$ in air, Corros. Sci. 43 (2001) 1095, https://doi.org/10.1016/ S0010-938X(00)00142-6

18. Z. M. Sun, Progress in research and development on MAX phases: a family of layered ternary compounds, Int. Mater. Rev. 56 (2011) 143, https://doi.org/10.1179/ $1743280410 Y .0000000001$

19. K. Schwarz, P. Blaha, and G. K. H. Madsen, Electronic structure calculations of solids using the WIEN2k package for material sciences, Comput. Phys. Commun. 147 (2002) 71, https: //doi.org/10.1016/S0010-4655(02)00206-0

20. P. Blaha et al., WIEN2k: An APW+lo program for calculating the properties of solids, J. Chem. Phys. 152 (2020) 074101, https://doi.org/10.1063/1.5143061

21. J. P. Perdew and Y. Wang, Accurate and simple analytic representation of the electron-gas correlation energy, Phys. Rev. B 45 (1992) 13244, https://doi.org/10.1103/ PhysRevB.45.13244

22. W. Kohn and L. J. Sham, Self-Consistent Equations Including Exchange and Correlation Effects, Phys. Rev. 140 (1965) A1133, https://doi.org/10.1103/PhysRev.140. A1133

23. H. J. Monkhorst and J. D. Pack, Special points for Brillouinzone integrations, Phys. Rev. B 13 (1976) 5188, https:// doi.org/10.1103/PhysRevB.13.5188

24. F. D. Murnaghan, The Compressibility of Media under Extreme Pressure, Proc. Natl. Acad. Sci. 30 (1944) 244, https : //doi.org/10.1073/pnas.30.9.244.

25. A. Yakoubi, O. Baraka, and B. Bouhafs, Structural and electronic properties of the Laves phase based on rare earth type $\mathrm{BaM}_{2}(\mathrm{M}=\mathrm{Rh}, \mathrm{Pd}, \mathrm{Pt})$, Res. Phys. 2 (2012) 58, https: //doi.org/10.1016/j.rinp.2012.06.001

26. H. R. Schober and P. H. Dederichs, (reference is incomplete)

27. D. Strauch, (reference is incomplete)

28. S. I. Sukhoruchkin and Z. N. Soroko, (reference is incomplete)

29. D. Strauch, (reference is incomplete)

30. M. Mebrek et al., Theoretical Investigation of Electronic Structures, Elastic, and Magnetic Properties of $\mathrm{Rh}_{2} \mathrm{CrGe}$ FullHeusler Alloy, Acta Phys. Pol. A 136 (2019) 454, https: //doi.org/10.12693/APhysPolA.136.454

31. A. Yakoubi, H. Mebtouche, M. Ameri, and B. Bouhafs, Structure and Bonding of Nanolayered Ternary Phosphides, Mater. Sci. Appl. 2 (2011) 1383, https://doi.org/10.4236/ msa.2011.210187. 
32. M. Born, On the stability of crystal lattices, Math. Proc. Camb. Philos. Soc. 36 (1940) 160, https : //doi .org/10. $4236 / \mathrm{msa} .2011 .210187$

33. I. R. Shein and A. L. Ivanovskii, Structural, elastic, electronic properties and Fermi surface for superconducting $\mathrm{Mo}_{2} \mathrm{GaC}$ in comparison with $\mathrm{V}_{2} \mathrm{GaC}$ and $\mathrm{Nb}_{2} \mathrm{GaC}$ from first principles, Physica C 470 (2010) 533, https: / / doi .org/10.1016/ j.physc.2010.04.010

34. M. S. Islam and A. Islam, Structural, elastic, electronic and optical properties of a new layered-ternary $\mathrm{Ta}_{4} \mathrm{SiC}_{3}$ compound, Physica B 406 (2011) 275, https: / / doi .org/10.1016/ j.physb.2010.10.067

35. J. Wang, J. Wang, Y. Zhou, and C. Hu, Phase stability, electronic structure and mechanical properties of ternary-layered carbide $\mathrm{Nb}_{4} \mathrm{AlC}_{3}$ : An ab initio study, Acta Mater. 56 (2008) 1511, https://doi.org/10.1016/j. actamat.2007.12.003
36. M. F. Cover, O. Warschkow, M. M. M. Bilek, and D. R. McKenzie, A comprehensive survey of $\mathrm{M}_{2} \mathrm{AX}$ phase elastic properties, J. Phys.: Condens. Matter 21 (2009) 305403, https: //doi.org/10.1088/0953-8984/21/30/305403

37. S. F. Pugh, XCII. Relations between the elastic moduli and the plastic properties of polycrystalline pure metals, London Edinburgh Dublin Philos. Mag. J. Sci. 45 (1954) 823, https: //doi.org/10.1080/14786440808520496

38. I. N. Frantsevich, Ref. B. (reference is incomplete)

39. Z. Sun, D. Music, R. Ahuja, and J. M. Schneider, Theoretical investigation of the bonding and elastic properties of nanolayered ternary nitrides, Phys. Rev. B 71 (2005) 193402, https : //doi.org/10.1103/PhysRevB.71.193402

40. I. R. Shein and A. L. Ivanovskii, Elastic properties of superconducting MAX phases from first-principles calculations, Phys. Status Solidi B 248 (2011) 228, https://doi.org/10. $1002 /$ pssb.201046163 